\title{
The COVID-19 pandemic, short-sale ban, and market efficiency: empirical evidence from the European equity markets
}

\author{
Seungho Lee ${ }^{1}$ (1)
}

Revised: 6 November 2021 / Accepted: 13 December 2021 / Published online: 28 January 2022

(c) The Author(s), under exclusive licence to Springer Nature Limited 2021

\begin{abstract}
This study looks at the inefficiency of stock indices of France, Italy, and Spain around their financial regulatory authorities' short-sale ban during the COVID-19 pandemic crisis. The empirical analysis of this study provides evidence of price predictability of the basis of futures contract prior to the short-sale restriction. Moreover, the results show a significant underpricing in futures contracts of FTSE MIB and IBEX35 indices while the two months of short-sale banned period. These findings suggest that prohibiting short selling during the market downturn might undermine the stock markets' efficiency and generate arbitrage opportunities for speculative investors.
\end{abstract}

Keywords Speculation · Efficient markets $\cdot$ Futures arbitrage $\cdot$ COVID-19

JEL Classification G11 $\cdot \mathrm{G} 12 \cdot \mathrm{G} 14 \cdot \mathrm{G} 18 \cdot \mathrm{F} 21$

\section{Introduction}

Traditionally, short selling has been understood to enhance market efficiency by reducing turbulence in volatility. However, after experiencing several financial crises for the last two decades, short sale has also been accused of menace for financial market stability. More specifically, financial regulators observed short selling's speculative nature, which possibly causes downward price pressure and consequently threatens market stability. In response to this concern, the US Securities and Exchange Commission (SEC) had temporarily banned short sales in stocks of US financial institutions during the 2008 financial crisis. In September 2008, the SEC placed two emergency orders, (1) prohibiting short selling of financial stocks, and (2) requiring institutional money managers to report short sales to the SEC weekly. ${ }^{1}$ However, the ban has been deemed as an ineffective remedy to slow down the dramatic decline of the stock prices over the crisis period, and accordingly was expired on October 8,2008 , lasting less than one month. In light of this experience, the SEC considered a circuit breaker for short sales as

Seungho Lee

seungho.lee@abdn.ac.uk

1 Business School, King's College, University of Aberdeen, Aberdeen AB24 3FX, Scotland, UK an alternative tonic for abusive price manipulation. ${ }^{2}$ Consequently, the USA has not indicated to consider a ban on short selling against the increasing volatilities in the stock markets caused by the COVID-19 pandemic crisis in early 2020. Instead, the US government and the Fed chose the Coronavirus Relief Fund, the Coronavirus Aid, Relief, and Economic Security (CARES) Act, and quantitative easing to defend the economy from the unprecedented shock.

On the other hand, in the recent debate concerning stock market stabilization and reducing extreme volatilities during the COVID-19 pandemic period, several European and Asian financial regulatory authorities chose the short-sale ban as a tool to react to the pandemic crisis. On March 16, 2020, the European Securities and Markets Authority (ESMA) required all short positions larger than $0.1 \%$ of the issued share capital traded on an E.U. to be reported to the relevant national regulators. Following the announcement, the Autorité des Marchés Financiers (AMF), Commissione Nazionale per le Società e la Borsa (CONSOB), Comision Nacional Del Mercado de Valores (CNMV), and the Financial Services and Markets Authority (FSMA) introduced a temporary and partial ban of short selling.

\footnotetext{
${ }^{1}$ See Emergency Order, Release No. 34-58592 (https://www.sec.gov/ rules/other/2008/34-58592.pdf).

2 See Amendments to Regulation SHO No. 34-61595 (https://www. sec.gov/rules/final/2010/34-61595.pdf).
} 
Table 1 List of major shortsale bans during COVID-19 pandemic crisis

\begin{tabular}{lllll}
\hline Country & Index & Start & End & \\
\hline Austria & ATX & March-18-20 & May-18-20 & Extended from April 18, 2020 \\
Belgium & BFX & March-17-20 & May-18-20 & Extended from April 17, 2020 \\
France & CAC40 & March-18-20 & May-18-20 & Extended from April 16, 2020 \\
Greece & ATG & March-18-20 & May-18-20 & Extended from April 24, 2020 \\
Italy & FTSE MIB & March-18-20 & May-18-20 & Early termination June 18, 2020 \\
Spain & IBEX & March-17-20 & May-18-20 & Extended from April 17, 2020 \\
Turkey & BIST50 & June-30-20 & February-12-21 & For BIST-50 Index stocks only \\
Indonesia & IDX & March-02-20 & February-28-21 & \\
Malaysia & KLSE & March-24-20 & December-31-20 & \\
Taiwan & TWSE & March-20-20 & June-19-20 & Early termination from June 30, 2020 \\
South Korea & KOSPI & March-16-20 & April-30-21 & Extended from September 15, 2020 \\
\hline
\end{tabular}

This table shows a list of indices subject to the short-sale ban during the market downturn caused by the COVID-19 pandemic crisis. In most cases, the curbs lasted either longer or shorter than their original plan. Austria, Belgium, France, Greece, Spain, and South Korea extended the ban for extended periods, while Italy and Taiwan terminated the ban prior to the planned date
Unlike the US case in 2008, the European stock markets' dramatic stock price slides had been halted, and the ESMA and the security regulators terminated the restriction on April 18, 2020. The action was similar in Asia, where the impact of the COVID-19 pandemic was prior to Europe. Representatively, Indonesia (March 2, 2020), South Korea (March 16, 2020), Malaysia (March 18, 2020), and Taiwan (March 20, 2020) announced curbs on short selling in their stock exchanges in March 2020 in response to the COVID-19 pandemic crisis. Taiwan terminated the temporary regulation on June 19, 2020, earlier than the original plan. The other three Asian countries carried the policy to the end of the year. Especially, South Korea lifted the ban on May 2, 2021, lasting the curb for longer than a year. While the extent of the regulation is different from that of the USA in 2008, all these regulations aim to maintain investor confidence and to stabilize the equity market in common. Please see Table 1 for the list of the short-sale ban in 2020 .

The focus of this study is investigating the effects of the European security regulators' short-sale ban order on the efficiency and stability of the stock markets in Europe. The research also attempts to suggest empirical evidence for the costs and benefits of the short-selling restrictions in 2020 . Most empirical studies about short-selling regulation are focused on the US case in 2008, and a relatively smaller number of empirical studies assess the results of the European short-sale prohibition. However, the results of existing studies that are most likely to address the US cases might cause inaccurate or incompatible political implications for the other stock markets. More specifically, the emergency order in the USA in November 2008 was only for stocks of financial institutions. In contrast, the short-sale bans in European countries cover the majority number of stocks in the markets regardless of their sector. Furthermore, the market capitalization, trading volume, and relevant regulations of the US stock exchanges are different from those of Europe.

By analyzing the curbs of European financial regulators in 2020, this study attempts to highlight the similarities and differences of the effects of short-sale prohibitions in the USA and Europe. I believe this paper provides additional empirical findings that were not captured by existing studies and suggests important policy implication for financial market regulators that consider policies to limit speculative abuse of short sales in their equity markets.

The remainder of the paper is organized as follows: "Literature review and research background" section provides a review of the relevant literature and historical background of negative interest rates. "Data description and methodologies" section presents a description of the data and outlines the methodological approaches. The empirical results are reported in "Results" section, and "Discussion: why France was different?" section provides further discussion. The paper concludes with a summary in "Conclusion" section.

\section{Literature review and research background}

Market stabilization has been identified as the key function of the short sale. This traditional view was derived from the discussion of the overreaction effect of Miller (1977). The study shows theoretical evidence of stock overprice when short selling is constrained, implying that short sales enhance the stock market efficiency. Numerous studies provide results that are consistent with Miller's results. For example, Boehme et al. (2009) asserts that when the stocks are overvalued when they are subject to short-sale constraints and divergence of investors' opinions. Chang et al. (2007) show that short-sale constraints are likely to lead to the overvaluation of stocks by analyzing Hong Kong's 
case. Moreover, the study provides evidence that the overvaluation is more considerable when the stock experiences a higher degree of divergence in investors' opinions. Relatively recent studies, including Boehmer and Wu (2013), suggest that the stock prices are more accurate when short selling is not constrained. They insist that the prices tend to be accurate if shorting flow in the market is large. Several researchers argue that shorting activities also contribute to market efficiency by providing relevant information to investors. Representatively, Christophe et al. (2004) insist that short selling gives an important signal to the investors, suggesting that financial market regulators may need to disclosure short selling to a larger extent. Besides, some studies point out that short sales contribute to firms' management by providing regulatory tools in corporate governance. For example, Massa et al. (2015) suggest that short selling might work as an external governance tool to restrain managers by showing a negative relationship between the threat of short selling and earnings management.

Consistent with these studies, a number of studies (see Autore et al. 2011; Battalio and Schultz 2011; Battalio et al. 2012; Boehmer et al. 2013) point out that the SEC's shortselling ban on financial stocks in 2008 was not deemed to be successful in terms of market stabilization. Nonetheless, the curb was imposed by many financial regulatory authorities in Europe and Asia during the market downturn period caused by the COVID-19 pandemic crisis. Numerous studies provide supportive empirical evidence for the regulation by addressing possible side effects of short selling. For example, Engelberg et al. (2018) point out that many risks accompany short selling in the market. They also provided evidence that stocks with higher short-selling risk tend to have fewer short sales, lower price efficiency, and poorer returns. Government regulations against short sale represent such belief that the shorting stocks may deteriorate the volatilities in stock markets downturn. How were the results of those temporary short-selling ban? Several scholars implemented empirical analyses for those historical bans and found. Numerous studies question the regulations' effectiveness to stabilize the equity markets and point out several side effects of the policy. For example, Diamond and Verrecchia (1987) argue that short-sale restriction may slow down the price adjustment process of securities. Jones and Lamont (2002) find that stocks can be overpriced when short sellings are prohibited. Similarly, Bris et al. (2007) asserts that short-sale bans deteriorate the inefficiency of equity markets by causing overpricing of regulated stocks. Moreover, the study suggests that market returns are significantly less negatively skewed if short selling is prohibited or not practiced in the stock market by analyzing 46 equity markets worldwide. Beber and Pagano (2012) pointed out that the ban might slow the price discovery process, which may cause the overvaluation of regulated stocks. Furthermore, they analyze equity prices of 30 countries during the financial crisis and find no evidence of statistical differences in excess returns of stocks for which short sales were banned and permitted.

Liquidity and equity returns are other concerns in regulating short sales. According to Diamond and Verrecchia (1987), the regulations on short position deteriorate equity market liquidity. Grundy et al. (2012) observed significant declines in options volumes and extension of the bid-ask spread of stocks during the 2008 short-sale ban on the US financial stocks. Autore et al. (2011)'s focus is on the stock returns in the restricted period. They find evidence that the stocks' returns were poor when they had significant liquidity declines during the 2008 ban of the SEC. Barber and Pagano (2013) also find that bans were detrimental for liquidity, especially for equities with small capitalization and no listed options. More recently, Brogaard et al. (2017) argue that some high-frequency traders activities might deteriorate equity liquidity during the 2008 short-sale ban period. Siciliano and Ventouruzzo (2020) also suggest that prohibiting short sale decreases not only the market efficiency but also the liquidity of the regulated stocks.

On the other hand, some studies imply that the short-sale ban may be an appropriate remedy during equity markets are experiencing a downturn. For example, Appel and Fohlin (2010) argues that a short-sale ban improves market liquidity. McGavin (2010) asserts that regulating short sales might be effective to prevent significant declines in stock prices during the financial crisis. Similarly, Battalio et al. (2012) argue that banning short sales can avert equity price fall when the market is bearish. Chen et al. (2020a, b) found that the shot-selling ban may cause significant declines in put-option volume, implying that the ban might be effective in retarding declines in equity prices.

Whereas the above-mentioned studies focus mainly on excessive returns, volatilities in prices, and liquidity issues when the short sales are restricted, this study attempts to address the issue of informational efficiency of equity indices futures contracts during the curb. Primarily, the empirical analysis of this study focuses on the following two research questions: (a) can we identify the government's restrictions on short selling are associated with deviation from no-arbitrage bound (b) do prices deviate from no-arbitrage bounds that give rise to profitable trading opportunities?

However, responding to these questions by analyzing the findings of previous studies is difficult, as most of them are focusing on the SEC's emergency order in 2008 that was limited to financial stocks. In contrast, the short-sale restrictions of European stock exchanges were applied for a larger extent of equities. This study analyzes the three European countries, France, Italy, and Spain, where short selling was banned during the COVID-19 pandemic crisis period and the GDPs are relatively sizable. Additionally, the findings of this study can be differentiated from those of previous 
Table 2 Descriptive statistics for the index and futures prices in France, Italy, and Spain

\begin{tabular}{|c|c|c|c|c|c|c|}
\hline & \multicolumn{2}{|c|}{ France CAC40 } & \multicolumn{2}{|c|}{ Italy FTSEMIB } & \multicolumn{2}{|c|}{ Spain IBEX35 } \\
\hline & \multicolumn{2}{|c|}{$(1 / 18 / 2020-7 / 18 / 2020)$} & \multicolumn{2}{|c|}{$(1 / 18 / 2020-7 / 18 / 2020)$} & \multicolumn{2}{|c|}{$(1 / 17 / 2020-7 / 18 / 2020)$} \\
\hline & Index & Futures & Index & Futures & Index & Futures \\
\hline Mean & 4955.627 & 5546.346 & 19581.73 & 19526.77 & 7702.567 & 7672.001 \\
\hline Median & 4909.64 & 5529.63 & 19162.98 & 19076 & 7278.1 & 7255.6 \\
\hline Maximum & 6111.24 & 6673.5 & 25477.55 & 25465 & 10083.6 & 10076 \\
\hline Minimum & 3754.84 & 4318.92 & 14894.44 & 15009 & 6107.2 & 6015 \\
\hline SD & 641.6518 & 634.6491 & 2909.065 & 2937.417 & 1182.064 & 1196.803 \\
\hline Skewness & 0.468693 & 0.380765 & 0.567909 & 0.569055 & 0.842373 & 0.833644 \\
\hline Kurtosis & 2.145009 & 2.115591 & 2.11338 & 2.091503 & 2.203139 & 2.189446 \\
\hline Jarque-Bera & 8.518008 & 7.207814 & 10.98644 & 11.22182 & 18.37984 & 18.18665 \\
\hline Probability & 0.014136 & 0.027217 & 0.004115 & 0.003658 & 0.000102 & 0.000112 \\
\hline Sum & 629364.7 & 704386 & 2486879 & 2479900 & 978226 & 974344.1 \\
\hline Sum Sq. Dev. & $5.19 \mathrm{E}+07$ & $5.08 \mathrm{E}+07$ & $1.07 \mathrm{E}+09$ & $1.09 \mathrm{E}+09$ & $1.76 \mathrm{E}+08$ & $1.80 \mathrm{E}+08$ \\
\hline Observations & 127 & 127 & 127 & 127 & 127 & 127 \\
\hline
\end{tabular}

This table shows descriptive statistics for the three index and futures contracts prices. The two months prior to and after the short-sale ban period are considered for the analysis analyses of the ban in 2008, as the traits of shocks that cause the market downturn in 2020 are different from those in 2008. While some flaws in the financial system are thought to be the main cause of the 2008 financial crisis, an external and global shock hit the market in 2020. Therefore, it is expected that this research would shed light on the hidden dimension of the impact of the short-sale ban by providing an additional empirical analysis of the effects of the shortsale restrictions in the stock markets.

\section{Data description and methodologies}

\section{Data description}

The short-sale curbs of European financial authorities in 2020 started and terminated simultaneously with a day of advance in Belgium and Spain. The duration of the restrictions was about two months, from March 18 to May 18, 2020. Considering the size of the economies, France, Italy, and Spain are considered as their GDPs are larger than 1 trillion USD. The historical index prices and futures prices of CAC40 (France), FTSE MIB (Italy), and IBEX35 (Spain) in the restricted period are collected for the analysis. Futures contract data are discrete as each contract has different maturity dates with the term of three months. Thus, the data series are rolled over at their expiration dates. For comparison, the same data of two months before and after the shortsale ban are also obtained from the Bloomberg DataStream. See Table 2 for the descriptive statistics.

\section{Speculative efficiency tests}

This study first questions whether or not future prices serve as valid predictors of spot prices changes for speculative tradings. To answer this, the Fama (1984) and the Fama and French (1987) regression approach with "adding-up" constraints has been implemented in the study. The two equations to be estimated are following:

$P_{t+1}-P_{t}=\alpha_{1}+\beta_{1}\left(F_{t}-P_{t}\right)+\varepsilon_{1, t+1}$

and

$F_{t}-P_{t+1}=\alpha_{2}+\beta_{2}\left(F_{t}-P_{t}\right)+\varepsilon_{2, t+1}$

where $P_{t}$ and $F_{t}$ are the spot and future value of the index at time $t$, respectively. $F_{t}-P_{t}$ defines the basis and $F_{t}-P_{t+1}$ refers to the risk premium at time $t$. Fama and French (1987) outline the "adding-up" constraints require the estimated intercept terms $\alpha_{1}$ and $\alpha_{2}$ and sum to zero, and the sum of estimated slope terms $\beta_{1}$ and $\beta_{2}$ to be equal to 1 . From Eq. (1), we can infer that the basis, $F_{t}-P_{t}$ includes the index value changes in the future, if $\beta_{1}$ is positive and significant. Similarly, the index futures price has power to predict index price in the future, as long as the data generate a positive and significant estimate of $\beta_{2}$. In addition, the Wald test is implemented to verify the unbiasedness of the predictors. The joint hypothesis for the tests is $\alpha_{i}=0, \beta_{i}=1$, and $\alpha_{i}=0$, $\beta_{i}=1$, where $\mathrm{i}$ is the number of the equation. ${ }^{3}$

\footnotetext{
${ }^{3}$ See III. The Basis: Forecast Power and Premiums of Fama and French (1987). This approach has been widely used as a benchmark test in speculative efficiency studies for a wide range of futures products. See e.g. Switzer and El-Khoury (2007), Stevens (2013), and Asche et al. (2016).
} 


\section{Futures-spot arbitrage efficiency tests}

In order to see whether those equity markets, where the short sale had temporarily banned, facilitate efficient pricing through arbitrage during the short-sale ban period, the costof-carry model is used (e.g., MacKinlay and Ramaswamy 1988; Bhatt and Cakici 1990; Switzer et al. 2000; Andani et al. 2009; Switzer et al. 2013). Mispricing is defined as the difference between the futures price at time $t$ with maturity $T$ and the arbitrage-free expected futures price of the contract:

$x_{t}=\left(F_{(t, T)}-F_{(t, T)}^{e}\right) / P_{t}$

$F_{(t, T)}$ and $P_{t}$ refer to the futures price and the index price at time $t$ with maturity $T$, respectively. $F_{(t, T)}^{e}=P_{t} e^{r f *(t-T)}$ defines the arbitrage-free expected price of the futures contract, where $r f$ is the risk-free rate. In this study, the 3-month each government's bond yield is regarded as $r f$. The mispricing term $x_{t}$ would be a gauge of inefficiency, which can be indicative of an arbitrage opportunity. This research's focus is whether or not the inefficiency deteriorates when financial regulators banned short selling. For investigating the existence of arbitrage opportunity in the three European stock markets during the regulated period, regression analyses are implemented as follows:

$x_{t}=\alpha+\beta \cdot \operatorname{ban}_{t}+\varepsilon_{t}$

where ban $_{t}$ is a dummy variable with a value of 1 for the days of short-sale ban and 0 otherwise. Prior to the regression, two different standard unit root tests, augmented Dickey-Fuller (ADF) and Phillips-Perron (PP), are performed for the mispricing term $x_{t}$ to verify the stationarity of the data.

\section{Results}

\section{Speculative efficiency test: results of Fama (1984) model with the adding-up constraints}

An essential prerequisite for performing the Fama (1984) model with the Fama and French (1987) adding up constraints is the stationarity of the data series. In order to confirm this condition, ADF and PP tests are performed for the data of three indices. Table 3 presents the results.

The table shows that the basis, the risk premium, and the change in the spot prices data series of Italy's FTSE MIB and Spain's IBEX35 indices are stationary, regardless of the covered period. For CAC40 index, the test statistics do not reject the existence of the unit root process in the data series. However, the results of both ADF and PP test for 1st differential of the data series indicate that the data are stationary. Therefore, the 1 st differentials of the data series are used for the regression analysis of CAC40.

Table 4 displays the results of the OLS estimation of Fama (1984)'s Eqs. (1) and (2) with the adding-up constraints suggested by Fama and French (1987). According to the table, the basis might contain some information about the spot price change of the CAC40 index during the shortsale ban period. On the other hand, the coefficients for the basis are significant in the two months of pre-banned periods in Italy and Spain, implying that the basis might have some power to predict price changes of FTSE MIB and IBEX 35 indices before the restriction. When it comes to Eq. (2), the results are upside down. The basis might include some information about risk premium before the ban in France, and possible predictabilities are observed while the governments are prohibiting the short selling in Italy and Spain.

The Wald test results provide somewhat mixed evidence of predicting power of the basis. As shown in Table 5, the results joint test for $\alpha_{2}=0, \beta_{2}=1$, and $\beta_{2}=1$ is significant at $10 \%$ of the level for pre two months of CAC40. The unbiasedness of predictors for FTSE MIB and IBEX35 spot price changes is rejected as the joint test for $\alpha_{1}=0, \beta_{1}=1$ and $\alpha_{1}=0, \beta_{1}=1$ is significant for two months of the pre-shortsale ban period. However, the results support the unbiasedness of the predictor in Eq. (2) when the short selling was banned in Italy and Spain. These results imply that changes in the basis are reflected as commensurate changes in the futures risk premium. However, it can be referred that the basis overestimates the change in spot prices.

\section{Futures-spot arbitrage test}

Do the regulations on short sales deteriorate the inefficiency of the stock markets? To respond this question, the mispricing of the indices defined in Eq. (3) is analyzed for the six-month period. Table 6 presents descriptive statistics of the mispricing term and the absolute value of the mispricing term.

The negative averages of $x$ in Italy and Spain indicate futures underpricing. Unlike these two, mispricing of the CAC40 index is positive for the entire six months of period. The statistics show negative skewness in common, indicating that distributions of $x$ are biased for all the indices, being consistent with Bris et al. (2007)'s observation.

This study's focus here is on the impact of the shortsale ban issue: Is the short-sale ban a significant factor that affects such futures mispricing for the equity indices? A common inference from results of previous studies (see Jones and Lamont 2002; Bris et al. 2007; Barber and Pagano 2013 ) is that the regulation would have a significant retardant on the price discovery process, and therefore, market 
Table 3 Unit root test statistics for Fama (1984) model with Fama and French (1987) constraints

\begin{tabular}{|c|c|c|c|c|c|c|}
\hline & \multicolumn{2}{|c|}{ Unit root test } & Overall 6 months & Pre 2 months & Banned period & Post 2 months \\
\hline \multicolumn{7}{|c|}{ Panel A: France CAC 40 index } \\
\hline \multirow[t]{4}{*}{ Basis (x) } & $\mathrm{ADF}$ & Level & -2.126 & -1.974 & -2.197 & $-3.772 *$ \\
\hline & & 1st Dif. & $-16.907 * * *$ & $-7.289 * * *$ & $-7.283^{* * *}$ & $-7.461 * * *$ \\
\hline & PP & Level & -2.713 & -1.916 & -2.130 & $-3.756^{*}$ \\
\hline & & 1st Dif. & $-20.271 * * *$ & $-12.624 * * *$ & $-7.421 * * *$ & $-21.961 * * *$ \\
\hline \multirow[t]{2}{*}{ Change in spot $(\mathrm{y} 1)$} & $\mathrm{ADF}$ & Level & $-10.984 * * *$ & $-6.779 * * *$ & $-6.759 * * *$ & $-6.897 * * *$ \\
\hline & PP & Level & $-11.059 * * *$ & $-6.779 * * *$ & $-7.635 * * *$ & $-6.893 * * *$ \\
\hline \multirow[t]{2}{*}{ Risk premium (y2) } & $\mathrm{ADF}$ & Level & $-11.089 * * *$ & $-7.309 * * *$ & $-6.665 * * *$ & $-6.950 * * *$ \\
\hline & $\mathrm{PP}$ & Level & $-11.153^{* * *}$ & $-7.304 * * *$ & $-7.563 * * *$ & $-6.937 * * *$ \\
\hline \multicolumn{7}{|c|}{ Panel B: Italy FTSE MIB index } \\
\hline \multirow[t]{4}{*}{ Basis (x) } & $\mathrm{ADF}$ & Level & $-4.101 * * *$ & $-8.878 * * *$ & -3.190 & -3.157 \\
\hline & & 1st Dif. & - & - & $-4.551 * * *$ & $-10.047 * * *$ \\
\hline & PP & Level & $-4.142 * * *$ & $-9.630 * * *$ & $-3.377 *$ & $-3.213 *$ \\
\hline & & 1st Dif. & - & - & $-4.551 * * *$ & $-10.187 * * *$ \\
\hline \multirow[t]{2}{*}{ Change in spot $(y 1)$} & $\mathrm{ADF}$ & Level & $-11.614 * * *$ & $-22.745 * * *$ & $-6.709 * * *$ & $-7.025 * * *$ \\
\hline & PP & Level & $-11.733 * * *$ & $-\mathbf{5 3 . 7 8 3}^{* * *}$ & $-7.159 * * *$ & $-7.020 * * *$ \\
\hline \multirow[t]{2}{*}{ Risk premium (y2) } & $\mathrm{ADF}$ & Level & $-6.208 * * *$ & $-7.402 * * *$ & $-6.585 * * *$ & $-6.782 * * *$ \\
\hline & PP & Level & $-11.044 * * *$ & $-7.402 * * *$ & $-6.737 * * *$ & $-6.781 * * *$ \\
\hline \multicolumn{7}{|c|}{ Panel C: Spain IBEX35 index } \\
\hline \multirow[t]{2}{*}{ Basis ( $\mathrm{x})$} & $\mathrm{ADF}$ & Level & $-3.576 * * *$ & $-7.572 * * *$ & $-5.430 * * *$ & $-7.025 * * *$ \\
\hline & PP & Level & $-5.047 * * *$ & $-7.420 * * *$ & $-5.359 * * *$ & $-7.258 * * *$ \\
\hline \multirow[t]{2}{*}{ Change in spot (y1) } & $\mathrm{ADF}$ & Level & $-10.942 * * *$ & $-7.215 * * *$ & $-8.376^{* * *}$ & $-5.992 * * *$ \\
\hline & PP & Level & $-10.975 * * *$ & $-7.755 * * *$ & $-8.434 * * *$ & $-5.995 * * *$ \\
\hline \multirow[t]{2}{*}{ Risk premium (y2) } & $\mathrm{ADF}$ & Level & $-5.650 * * *$ & $-5.769 * * *$ & $-9.651 * * *$ & $-6.561 * * *$ \\
\hline & $\mathrm{PP}$ & Level & $-10.827 * * *$ & $-5.769 * * *$ & $-10.331 * * *$ & $-6.561 * * *$ \\
\hline
\end{tabular}

To confirm the stationary of the data series, two standard unit root tests are implemented for the basis, the change in spot, and the risk premium of Fama (1984)'s OLS estimation. The data series is divided into three periods (pre-ban, ban, and post-ban period). For the data series with unit root process, the 1st differential of the data is re-examined $* * * p<0.01 ; * * p<0.05 ; * p<0.1$ inefficiency might be increased. This phenomenon is also observed in these three equity markets' data series.

Figures 1 and 2 are line graphs of the three markets' mispricing term and the absolute value of mispricing terms, respectively. The short-sale ban period is shaded. As shown in the figures, both mispricing and absolute mispricing exhibit a significant spike at the beginning of the ban. While CAC40 shows futures overpricing, futures contracts of FTSE MIB and IBEX35 underpriced the indices. In order to capture this impact statistically, the regression analysis is performed using a dummy variable as suggested in Eq. (4). Prior to the estimation, the standard ADF and PP unit root tests are implemented to confirm the mispricing term data series' stationarity.

As can be seen in Table 7, the data series of the mispricing and the absolute value of mispricing are stationary for both FTSE MIB and IBEX35 indices. However, unit root processes are observed for CAC40's mispricing and the absolute value of mispricing data. As the first differential of the data series shows significant ADF and PP statistics at $1 \%$ level, rejecting the existence of unit root process, the first differentiated data series are used for the CAC40 index's pricing efficiency analysis.

Panel A of Table 8 presents the regression results of daily futures mispricing term and the absolute value. As shown in the table, there is no significant statistical evidence that market inefficiency is increased or decreased for the CAC40 index during the short-sale ban period. However, the OLS estimation captures evidence of the futures underpricing of FTSE MIB and IBEX35 during the same period. The results show that both the mispricing term and the absolute value of the mispricing term have significant coefficients for the ban dummy variable. Mainly, negative coefficients for the mispricing term imply that the futures prices are significantly underpricing the spot index prices when the financial regulatory authorities prohibit the short sale.

For an aggregate analysis of these three indices, the mispricing data are pooled and regressed on the ban dummy variable. See Panel B of Table 8. For both regressions with fixed and random effects, the panel data show that the ban 


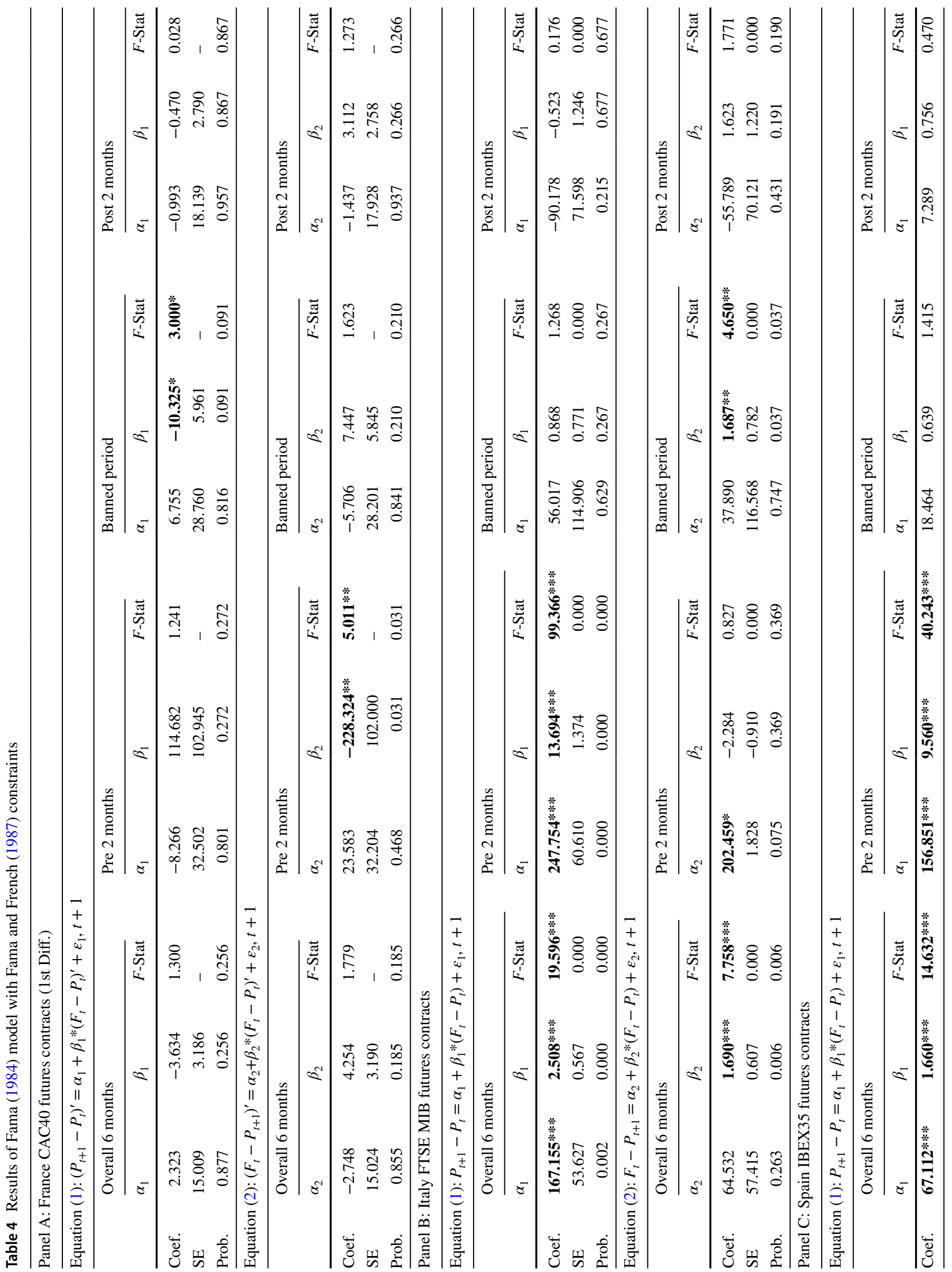




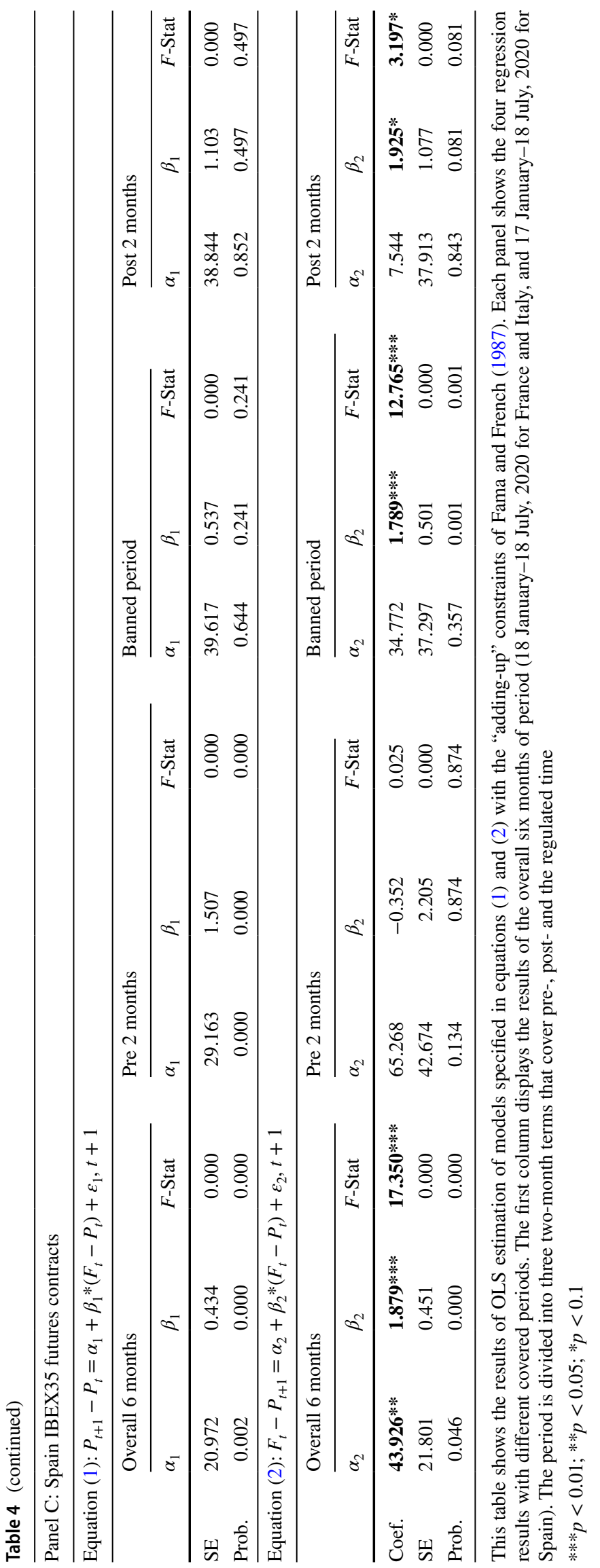




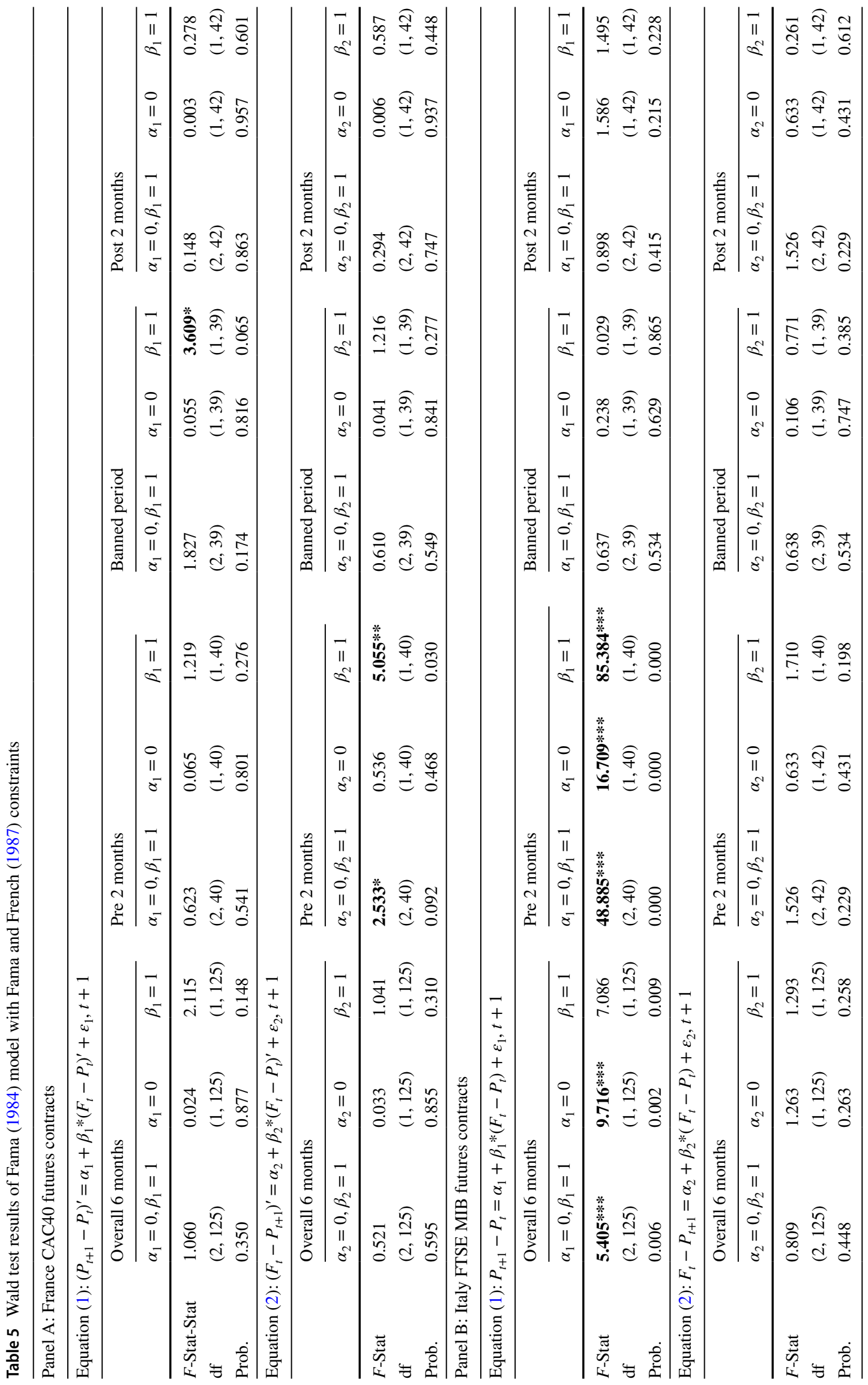




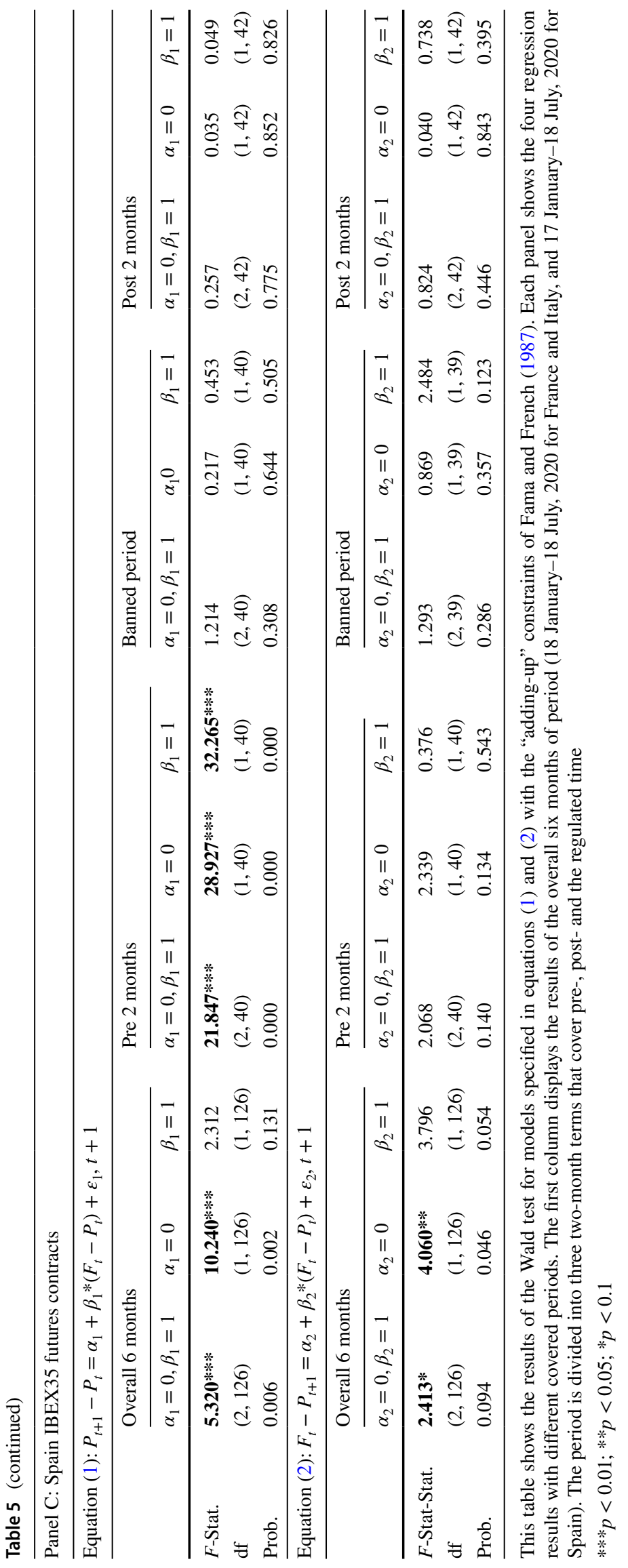


Table 6 Descriptive statistics of mispricing term and absolute value of mispricing term

\begin{tabular}{|c|c|c|c|c|c|c|}
\hline & \multicolumn{2}{|l|}{ France CAC40 } & \multicolumn{2}{|l|}{ Italy FTSEMIB } & \multicolumn{2}{|l|}{ Spain IBEX35 } \\
\hline & \multicolumn{2}{|c|}{$(1 / 18 / 2020-7 / 18 / 2020)$} & \multicolumn{2}{|c|}{$(1 / 18 / 2020-7 / 18 / 2020)$} & \multicolumn{2}{|c|}{$(1 / 17 / 2020-7 / 18 / 2020)$} \\
\hline & (1) Mispricing term & $\begin{array}{l}\text { (2) Abs. value of } \\
\text { mispricing term }\end{array}$ & (1) Mispricing term & $\begin{array}{l}\text { (2) Abs. value of } \\
\text { mispricing term }\end{array}$ & (1) Mispricing term & $\begin{array}{l}\text { (2) Abs. value of } \\
\text { mispricing term }\end{array}$ \\
\hline Mean & 0.121261 & 0.121261 & -0.00306 & 0.0037 & -0.00429 & 0.004796 \\
\hline Median & 0.127724 & 0.127724 & -0.00214 & 0.0024 & -0.0034 & 0.003594 \\
\hline Maximum & 0.150227 & 0.150227 & 0.014137 & 0.024108 & 0.007808 & 0.034541 \\
\hline Minimum & 0.091992 & 0.091992 & -0.02411 & $5.62 \mathrm{E}-06$ & -0.03454 & $5.38 \mathrm{E}-05$ \\
\hline $\mathrm{SD}$ & 0.016654 & 0.016654 & 0.004613 & 0.00411 & 0.005654 & 0.005227 \\
\hline Skewness & -0.69296 & -0.69296 & -1.26868 & 2.276068 & -2.3489 & 2.950819 \\
\hline Kurtosis & 2.125607 & 2.125607 & 8.595368 & 9.718128 & 11.70373 & 14.35359 \\
\hline Jarque-Bera & 14.20981 & 14.20981 & 199.7411 & 348.4837 & 521.7295 & 873.2439 \\
\hline Probability & 0.000821 & 0.000821 & 0 & 0 & 0 & 0 \\
\hline Sum & 15.4002 & 15.4002 & -0.38811 & 0.469906 & -0.54904 & 0.613937 \\
\hline Sum Sq. Dev. & $3.49 \mathrm{E}-02$ & $3.49 \mathrm{E}-02$ & $2.68 \mathrm{E}-03$ & $2.13 \mathrm{E}-03$ & $4.06 \mathrm{E}-03$ & $3.47 \mathrm{E}-03$ \\
\hline Observations & 127 & 127 & 127 & 127 & 128 & 128 \\
\hline
\end{tabular}

This table shows descriptive statistics for the mispricing term $\mathrm{x}$ and the absolute value of the term. The two months prior to and after the shortsale ban period are considered for the analysis

may significantly impact the mispricing term and the absolute value of mispricing changes. This result is consistent with the individual index analysis, endorsing the assertion that the short-sale prohibition may influence the stock market efficiency.

\section{Discussion: why France was different?}

Analysis of this research provides statistical evidence of (1) the basis has the power to predict changes of index prices pre-short-sale ban period, and (2) increasing inefficiency during the curb. However, the statistics show that the extent of the stock market efficiency differs by country. This is inconsistent with previous studies, including Rossi and Gunardi (2018) and Liao et al. (2019) that points out many similarities in stock market efficiency of developed European countries. A possible inference for the cause of this temporary divergence in market efficiency among the three stock markets might be the difference in the information of COVID-19 spread among the countries. Primarily, both Italy and Spain had been known notorious spots during the first wave of the pandemic. The level of investors' fear for the recession in the stock market might be higher in the two countries than in France at the beginning of the first wave of the pandemic. However, France has shown higher daily confirmed cases since April 2020. More importantly, the case count announced by France's health authority was overestimated and underestimated several times during the two months of the research period. The following figure compares the new daily confirmed cases in the three countries over the six months of period.

As shown in the Fig. 3, France has a relatively lower number of confirmed cases at the beginning. However, the data show several negative numbers at the end of March, which indicate a correction of announced numbers. For example, the confirmed daily cases of COVID-19 in France on the 4th of April, 2020 are -17,076, canceling out the previous 3.6 days of cases. (7636 cases on March 31, 4844 cases on April 1, 2102 cases on April 2, and 5225 cases on April 3). Over the research period, there are eight negative case counts in France data, while there were only 1 and 2 in Italy and Spain. By reviewing statistics, it can be inferred that the accuracy of COVID-19 counts data in France might be lower than those of the other two countries. This may imply that the investors of CAC40 might not have up-to-date information about the pandemic situation in France and consequently prevented investors from reacting appropriately and immediately against the 
CAC40 Mispricing (2020/01/18 - 2020/07/18)

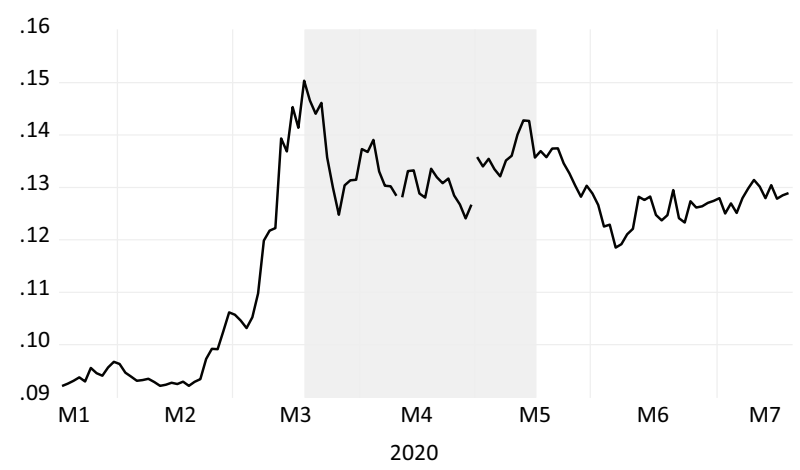

FTSE MIB Mispricing (2020/03/18 - 2020/05/18)

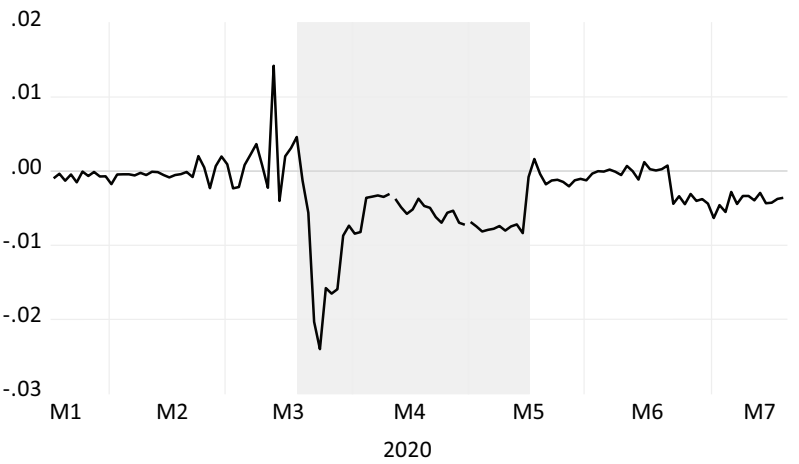

IBEX35 - Mispricing Term (2020/01/17 - 2020/05/18)

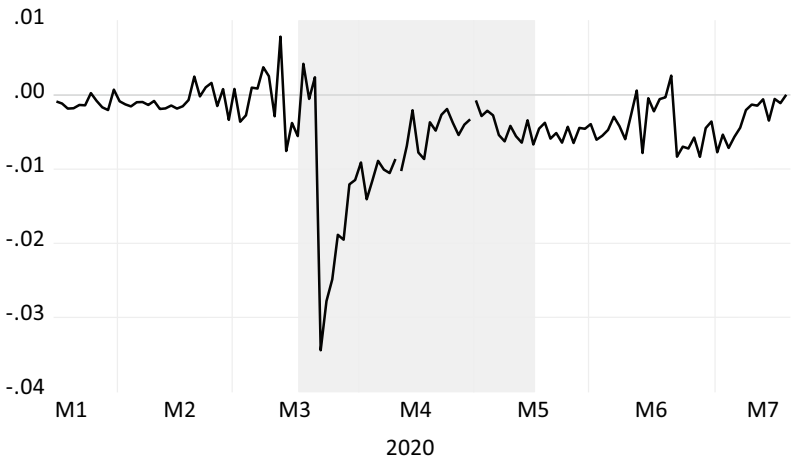

Fig. 1 Mispricing term of CAC40, FTSE MIB, and IBEX35
CAC40 Absolute Value of Mispricing (2020/01/18 - 2020/07/18)

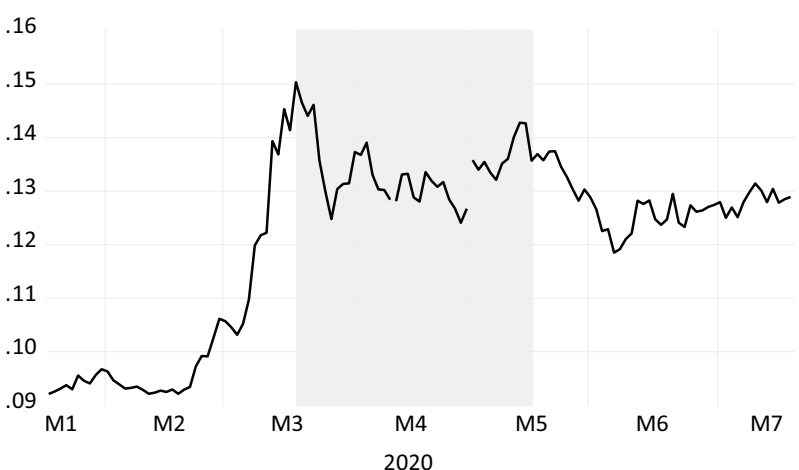

FTSE MIB Absolute Value of Mispricing (2020/01/18 - 2020/07/18)

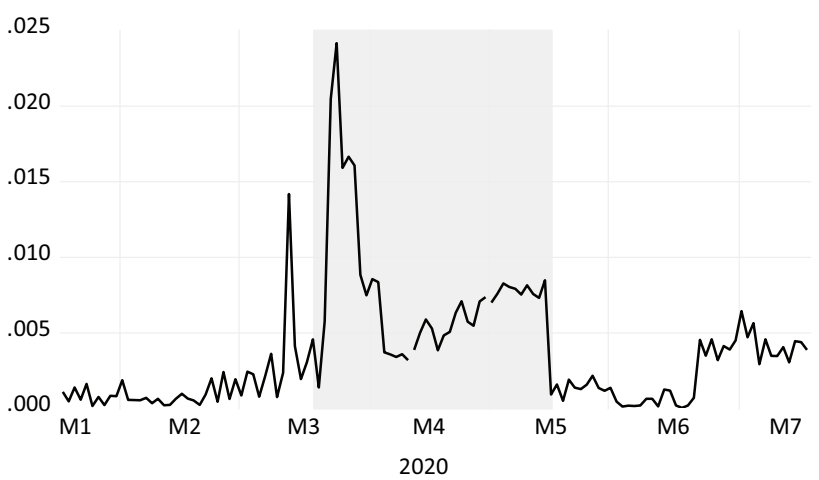

IBEX35 - Absolute Value of Mispricing (2020/01/17 - 2020/05/18)

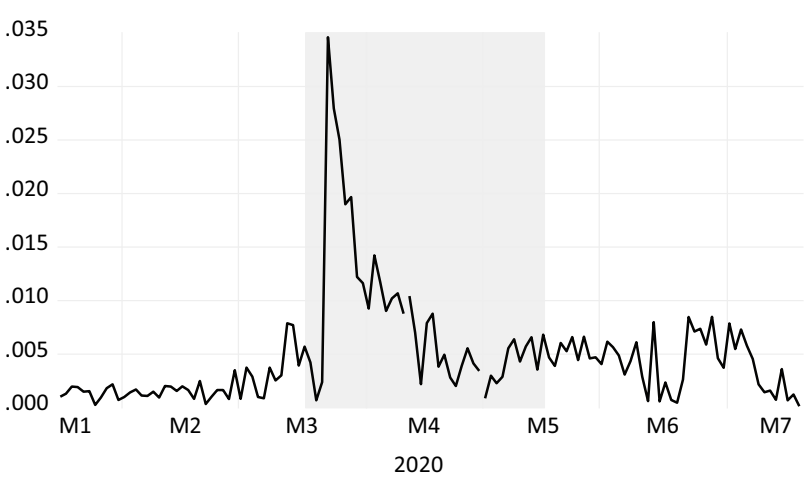

Fig. 2 Absolute value of mispricing term of CAC40, FTSE MIB, and IBEX35 
Table 7 Unit root test results of the futures mispricing during the short-sale ban period

\begin{tabular}{|c|c|c|c|c|c|c|}
\hline \multirow[t]{2}{*}{ Country } & \multicolumn{2}{|c|}{ Unit root test } & \multicolumn{2}{|c|}{ (1) Mispricing term } & \multicolumn{2}{|c|}{$\begin{array}{l}\text { (2) Absolute value of } \\
\text { mispricing term }\end{array}$} \\
\hline & & & Coef. & Prob. & Coef. & Prob. \\
\hline \multirow{4}{*}{$\begin{array}{l}\text { CAC40 } \\
\text { (France) }\end{array}$} & $\mathrm{ADF}$ & Level & -1.798 & 0.380 & -1.798 & 0.380 \\
\hline & & 1st Diff. & $-11.512 * * *$ & 0.000 & $-11.512 * * *$ & 0.000 \\
\hline & PP & Level & -1.832 & 0.364 & -1.832 & 0.364 \\
\hline & & 1st Diff. & $-11.523 * * *$ & 0.000 & $-11.523 * * *$ & 0.000 \\
\hline \multirow{2}{*}{$\begin{array}{l}\text { FTSE MIB } \\
\text { (Italy) }\end{array}$} & $\mathrm{ADF}$ & Level & $-4.160 * * *$ & 0.001 & $-3.673 * * *$ & 0.006 \\
\hline & $\mathrm{PP}$ & Level & $-4.181 * * *$ & 0.001 & $-3.526 * * *$ & 0.009 \\
\hline IBEX35 & $\mathrm{ADF}$ & Level & $-3.585 * * *$ & 0.007 & $-4.292 * * *$ & 0.001 \\
\hline (Spain) & PP & Level & $-5.049 * * *$ & 0.000 & $-4.167 * * *$ & 0.001 \\
\hline
\end{tabular}

To confirm the stationary of the data series, two standard unit root tests are implemented for the mispricing term and the absolute value of the term. The data series is divided into three periods (pre-ban, ban, and post-ban period), and the unit-root tests are implemted for the banned period. For the data series with unit root process, the 1st differential of the data is re-examined

$* * * p<0.01 ; * * p<0.05 ; * p<0.1$ market risk. Besides, several studies in the medical discipline also support this inference. Representatively, Pullano et al. (2021) criticize problems of COVID-19 testing policy and capacity of the health authority of France during the early stage of the pandemic.

Additional regression analyses are performed to capture the effect of this difference between France and the other two countries, following the methodological approach of comparable studies including Al-Awadhi et al. (2020), Ashraf (2020), Chen et al. (2020a, b), and Topcu and Gulal (2020). The models are specified as follows:

$x_{t}=\alpha+\beta \cdot$ New_Cases $_{t}+\varepsilon_{t}$

$x_{t}=\alpha+\beta \cdot$ New_Cases ${ }_{t}+\gamma \cdot$ Country $+\varepsilon_{t}$

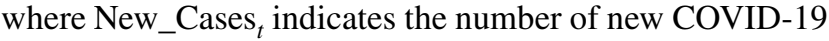
cases at time $t$, and Country is a dummy variable that has a value of 1 for French data and 0 otherwise. For Eq. (5), both fixed effect and random effect are considered.

Table 9 presents the results of the regression estimation. Panel A of the table provides evidence that the number of new cases may be a significant factor in stock market efficiency. A dilution of underpricing of CAC40 and overpricing of FTSE MIB and IBEX35 is also shown in the estimation of mispricing term, as the coefficient of
New_Cases, variable is not significant. A similar result is carried out from the regression with the random effect. Panel B shows the clear difference between the two groups of countries. The estimation indicates that Country variable is significant at the $1 \%$ level, supporting the difference in mispricing is apparent between CAC40 and the other

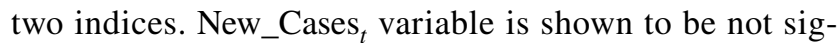
nificant, likely to be due to the overpricing and underpricing offsets between the two groups.

These results indicate that the differences between the CAC40 index and the other two indices during the shortsale ban period might be led by the difference in the pandemic-related information quality rather than the number of COVID-19 confirmed cases. This finding also alerts the possible side effect of the short-sale regulation when the credibility of information available in the market was damaged. The public can become skeptical about the numbers as the corrections are repeated, and the market participant may hesitate to consider the information in their investment decision making. Consequently, the decreased reflection of information can undermine the stock market's efficiency and generate arbitrage opportunities in the market. Accordingly, restrictions that can influence market efficiency might be more successful when the related social infrastructure functions synergistically and simultaneously due to the information sensitivity of the stock market. 
Table 8 Results of OLS regression estimation of daily futures mispricing with shortsale ban dummy

\begin{tabular}{|c|c|c|c|c|c|c|c|}
\hline & & \multicolumn{3}{|c|}{ (1) Mispricing term } & \multicolumn{3}{|c|}{$\begin{array}{l}\text { (2) Absolute value of mispricing } \\
\text { term }\end{array}$} \\
\hline & & Constant & Ban & $F$-Stat & Constant & Ban & $F$-Stat \\
\hline \multicolumn{8}{|c|}{ Panel A: Individual index analysis } \\
\hline \multirow{3}{*}{$\begin{array}{l}\text { CAC40 (France) } \\
\text { (1st Diff.) }\end{array}$} & Coef. & 0.000 & 0.001 & 0.078 & 0.001 & -0.001 & 0.936 \\
\hline & SE & 0.002 & 0.003 & - & 0.000 & 0.001 & - \\
\hline & Prob. & 0.991 & 0.781 & 0.781 & 0.187 & 0.335 & 0.335 \\
\hline \multirow[t]{3}{*}{ FTSE MBI (Italy) } & Coef. & $\mathbf{0 . 0 1 8} * * *$ & $-0.073 * * *$ & $227.485 * * *$ & $0.002 * * *$ & $0.006 * * *$ & 83.981*** \\
\hline & $\mathrm{SE}$ & 0.003 & 0.005 & - & 0.000 & 0.001 & - \\
\hline & Prob. & 0.000 & 0.000 & 0.000 & 0.000 & 0.000 & 0.000 \\
\hline \multirow[t]{3}{*}{ IBEX35 (Spain) } & Coef. & $0.043 * * *$ & $-\mathbf{0 . 0 2 8} * * *$ & $28.929 * * *$ & $\mathbf{0 . 0 0 3} * * *$ & $0.005 * * *$ & $35.269 * * *$ \\
\hline & SE & 0.003 & 0.005 & & 0.001 & 0.001 & - \\
\hline & Prob. & 0.000 & 0.000 & 0.000 & 0.000 & 0.000 & 0.000 \\
\hline \multicolumn{8}{|c|}{ Panel B: Pooled data analysis } \\
\hline \multirow{3}{*}{$\begin{array}{l}\text { Pooled data } \\
\text { (Fixed effect) }\end{array}$} & Coef. & $\mathbf{0 . 0 3 7} * * *$ & $0.002 * *$ & $3996.517 * * *$ & $0.040 * * *$ & $0.010 * * *$ & 4466.615*** \\
\hline & SE & 0.001 & 0.001 & - & 0.001 & 0.001 & - \\
\hline & Prob. & 0.000 & 0.038 & 0.000 & 0.000 & 0.000 & 0.000 \\
\hline \multirow{3}{*}{$\begin{array}{l}\text { Pooled data } \\
\text { (Random effect) }\end{array}$} & Coef. & 0.037 & $0.002 * *$ & $4.329 * *$ & 0.040 & $0.010 * * *$ & $93.685 * * *$ \\
\hline & SE & 0.051 & 0.001 & - & 0.048 & 0.001 & - \\
\hline & Prob. & 0.464 & 0.038 & 0.038 & 0.404 & 0.000 & 0.000 \\
\hline
\end{tabular}

This table shows the analysis of mispricing data of CAC40, FTSE MIB, IBEX35 with the ban dummy variable. Considering the start and end date of the short-sale ban in the three stock markets, the data of 17 January-18 July 2020 are considered. Panel A presents results of individual indices, and Panel B displays results of pooled regression. The pooled data regression is implemented with country fixed effect and random effect

$* * * p<0.01 ; * * p<0.05 ; * p<0.1$

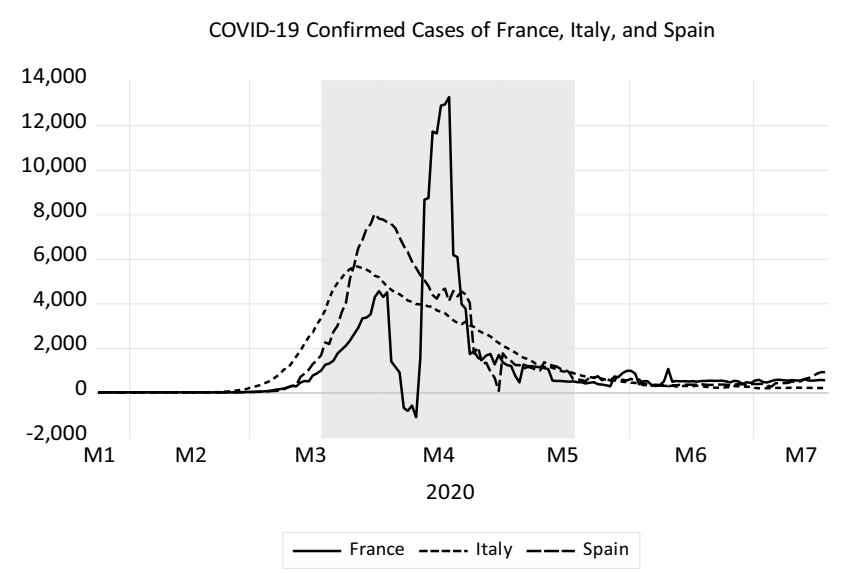

Fig. 3 COVID-19 daily new confirmed cases of France, Italy, and Spain. Data source: Our World in Data. (https://ourworldindata.org/ coronavirus assessed on May 30, 2021)

\section{Conclusion}

This study examines changes in the efficiency of the stock market indices of France, Italy, and Spain, where short selling is prohibited due to the unprecedented global pandemic crisis. The results of this study are diverging. CAC40 was overpriced during the short-sale ban period, while FTSE MIB and IBEX35 were underpriced. The outcomes also suggest that the inefficiency of the stock markets in Italy and Spain was significantly increased, implying that there might be an arbitrage opportunity during the two months of shortsale ban. The results of the French stock index are distinctive. The data analyses do not provide solid evidence that the efficiency market deteriorated during the curb. A possible explanation for this difference is the quality of the COVID19 information for the investors. It is a rational inference that the investors in the French stock market might not react appropriately against the catastrophe, and thus caused a price distortion to some extent.

The findings of this study suggest several policy implications. First of all, prohibiting short sale by the financial regulatory institution might not be the best remedy for market stabilization during the crisis. The empirical analysis of this research shows that the regulation might cause futures underpricing and increase the inefficiency of stock markets. This may result in futures price distortions and possibly undermine the hedging ability of various investments. 
Table 9 Results of OLS regression estimation of daily futures mispricing with daily COVID-19 confirmed cases

\begin{tabular}{|c|c|c|c|c|c|c|c|}
\hline & & \multicolumn{3}{|c|}{ (1) Mispricing term } & \multicolumn{3}{|c|}{ (2) Absolute value of mispricing term } \\
\hline & & Constant & New cases & $F$-Stat & Constant & New cases & $F$-Stat \\
\hline \multicolumn{8}{|c|}{ Panel A: Regression analysis with pooled data (fixed and random effect) } \\
\hline Pooled data & Coef. & $\mathbf{0 . 0 3 8} * * *$ & 0.000 & $3950.463 * * *$ & $0.041 * * *$ & $0.000 * * *$ & $4139.837 * * *$ \\
\hline \multirow[t]{2}{*}{ (Fixed effect) } & SE & 0.001 & 0.000 & - & 0.001 & 0.000 & - \\
\hline & Prob. & 0.000 & 0.865 & 0.000 & 0.000 & 0.000 & 0.000 \\
\hline \multirow{5}{*}{$\begin{array}{l}\text { Pooled data } \\
\text { (Random effect) }\end{array}$} & Coef. & 0.038 & 0.000 & 0.029 & 0.041 & $0.000 * * *$ & 59.584 \\
\hline & SE & 0.031 & 0.000 & - & 0.030 & 0.000 & - \\
\hline & Prob. & 0.222 & 0.864 & 0.864 & 0.170 & 0.000 & 0.000 \\
\hline & & \multicolumn{3}{|c|}{ (1) Mispricing term } & \multicolumn{3}{|c|}{ (2) Absolute value of mispricing term } \\
\hline & & Constant & New cases & Country & Constant & New cases & Country \\
\hline \multicolumn{8}{|c|}{ Panel B: Regression analysis with pooled data (country dummy variable) } \\
\hline \multirow[t]{3}{*}{ Pooled data } & Coef. & $0.121 * * *$ & 0.000 & $-0.125^{* * *}$ & $0.119 * * *$ & $0.000 * * *$ & $-0.117 * * *$ \\
\hline & SE & 0.001 & 0.000 & 0.001 & 0.001 & 0.000 & 0.001 \\
\hline & Prob. & 0.000 & 0.842 & 0.000 & 0.000 & 0.000 & 0.000 \\
\hline
\end{tabular}

This table shows the regression analysis of the pooled mispricing data, including CAC40, FTSE MIB, IBEX35. Considering the start and end date of the short-sale ban in the three stock markets, the data of 17 January-18 July 2020 are considered

$* * * p<0.01 ; * * p<0.05 ; * p<0.1$

\section{References}

Al-Awadhi, A.M., K. Alsaifi, A. Al-Awadhi, and S. Alhammadi. 2020. Death and contagious infectious diseases: Impact of the COVID-19 virus on stock market returns. Journal of Behavioral and Experimental Finance. https://doi.org/10.1016/j.jbef.2020. 100326.

Andani, A., J.A. Lafuente, and A. Novales. 2009. Liquidity and hedging effectiveness under futures mispricing: international evidence. Journal of Futures Markets 29(11):1050-1066.

Appel, I. and C. Fohlin. 2010. "Shooting the messenger?" The impact of short sale bans in Times of Crisis. Economics Working Paper Archive 574, The Johns Hopkins University, Department of Economics.

Asche, F., B. Misund, and A. Oglend. 2016. The spot-forward relationship in the Atlantic salmon market. Aquaculture Economics \& Management 20(2): 222-234.

Ashraf, B.N. 2020. Stock markets' reaction to COVID-19: Cases or fatalities?. Research in International Business and Finance. https://doi.org/10.1016/j.ribaf.2020.101249.

Autore, D.M., R.S. Billingsley, and T. Kovacs. 2011. The 2008 short sale ban: Liquidity, dispersion of opinion, and the cross-section of returns of US financial stocks. Journal of Banking \& Finance 35(9): 2252-2266.

Battalio, R., and P. Schultz. 2011. Regulatory uncertainty and market liquidity: The 2008 short sale ban's impact on equity option markets. Journal of Finance 66(6): 2013-2053.

Battalio, R., H. Mehran, and P. Schultz. 2012. Market declines: What is accomplished by banning short-selling?. Current Issues. 18(5): 1.

Beber, A. and M. Pagano. 2012. Short-selling bans around the world: Evidence from the 2007-09 crisis. Journal of Finance 68(1): 343381. https://doi.org/10.1111/j.1540-6261.2012.01802.x

Bhatt, S., and N. Cakici. 1990. Premiums on stock index futures - some evidence. Journal of Futures Markets 10: 367-375.

Boehme, R.D., B.R. Danielsen, and S.M. Sorescu. 2009. Short-sale constraints, differences of opinion, and overvaluation. Journal of Financial and Quantitative Analysis. 41(2): 455-487.
Boehmer, E., C.M. Jones, and X. Zhang. 2013. Shackling short sellers: The 2008 shorting ban. Review of Financial Studies. 26(6): $1363-1400$.

Boehmer, E., and J. Wu. 2013. Short selling and the price discovery process. The Review of Financial Sudies 26(2): 287-322.

Bris, A., W.N. Goetzmann, and N. Zhu. 2007. Efficiency and the bear: Short sales and markets around the world. Journal of Finance 62(3): 1029-1079.

Brogaard, J., and Hendershott, and Riordan, R. 2017. High frequency trading and the 2008 short-sale ban. Journal of Financial Economics 124(22): 22-42.

Chang, E.C., J.W. Cheng, and Y. Yu. 2007. Short-sales constraints and price discovery: Evidence from the Hong Kong market. Journal of Finance 62(5): 2097-2121.

Chen, Y.E., S.S. Chen, and R.K. Chou. 2020b. Short-sale constraints and options trading: Evidence from Reg SHO. Journal of Financial and Quantitative Analysis 55(5): 1555-1579.

Chen, Y., B. Kelly, and W. Wu. 2020a. Sophisticated investors and market efficiency: Evidence from a natural experiment. Journal of Financial Economics 138: 316-341. https://doi.org/10.1016/j. jfineco.2020.06.004.

Christophe, S.E., M.G. Ferri, and J.J. Angel. 2004. Short-selling prior to earnings announcements. Journal of Finance 59(4): $1845-1875$.

Diamond, D.W., and R.E. Verrecchia. 1987. Constraints on short- selling and asset price adjustment to private information. Journal of Financial Economics 18: 277-311.

Engelberg, J.E., A.V. Reed, and M.C. Ringgenberg. 2018. Short-selling risk. Journal of Finance. 73(2): 755-786.

Fama, E.F. 1984. Forward and spot exchange rates. Journal of Monetary Economics 14(3): 319-338.

Fama, E.F., and K.R. French. 1987. Commodity futures prices: Some evidence on forecast power, premiums and the theory of storage. Journal of Business. 60(1): 55-73.

Grundy, B.D., B. Lim, and P. Verwijmeren. 2012. Do option markets undo restrictions on short sales? Evidence from the 2008 shortsale ban. Journal of Financial Economics. 106: 311-348. 
Jones, C.M., and O.A. Lamont. 2002. Short-sale constraints and stock returns. Journal of Financial Economics 66: 207-239.

Liao, T.L., L.C. Tsai, M.C. Ke, Y.C. Chiang, and C.H. Hsu. 2019. Financial crisis and market efficiency: Evidence from European stock markets. European Journal of Finance 25(13): 1194-1210. https://doi.org/10.1080/1351847X.2019.1584579.

MacKinlay, C., and K. Ramaswamy. 1988. Index-futures arbitrage and the behavior of stock index futures prices. Review of Financial Studies 1: 137-157.

Massa, M., B. Zhang, and H. Zhang. 2015. The invisible hand of short selling: Does short selling discipline earnings management? Review of Financial Studies. 28(6): 1701-1736.

McGavin, K. 2010. Short selling in a financial crisis: The regulation of short sales in the United Kingdom and the United States. Northwestern Journal of International Law \& Business 30(1): 201-239.

Miller, E.M. 1977. Risk, uncertainty, and divergence of opinion. Journal of Finance 32(4): 1151-1168. https://doi.org/10.2307/23265 20.

Pullano, G., L. Di Domenico, C.E. Sabbatini, et al. 2021. Underdetection of cases of COVID-19 in France threatens epidemic control. Nature 590: 134-139. https://doi.org/10.1038/ s41586-020-03095-6.

Rossi, M., and A. Gunardi. 2018. Efficient market hypothesis and stock market anomalies: Empirical evidence in four European countries. Journal of Applied Business Research 34(1): 183-192. https://doi. org/10.19030/jabr.v34i1.10111.

Siciliano, G. and M. Ventoruzzo. 2020. Banning Cassandra from the market? an empirical analysis of short-selling bans during the Covid-19 crisis. European Company and Financial Law Review 17(3-4): 386-418. https://doi.org/10.1515/ecfr-2020-0019.

Stevens, J., 2013. Testing the efficiency of futures market for crude oil using weighted least squares. Applied Economics Letters 20(18): 1611-1613.
Switzer, L.N., and M. El-Khoury. 2007. Extreme volatility, speculative efficiency, and the hedging effectiveness of the oil futures markets. Journal of Futures Market 27: 61-84.

Switzer, L.N. and H. Fan. 2009. Screen based trading, the cost of carry, and futures market efficiency. Risk and Decision Analysis 1(2009): $57-71$.

Switzer, L.N., Q. Shan, and J.M. Sahut. 2013. The impact of derivatives regulations on the liquidity and pricing efficiency of exchange traded derivatives. Review of Futures Markets 21: 71-103.

Topcu, M., and O.S. Gulal. 2020. The impact of COVID-19 on emerging stock markets. Finance Research Letters 36: 101691. https:// doi.org/10.1016/j.frl.2020.101691.

Publisher's Note Springer Nature remains neutral with regard to jurisdictional claims in published maps and institutional affiliations.

Seungho Lee is a Lecturer (Assistant Professor) in Finance at the Business School of the University of Aberdeen. He has served as Director of the Online MSc Finance Programme, Deputy Exams Officer, Academic Integrity Committee Panel at the business school. Seungho published several academic articles in peer-reviewed finance journals, including Journal of International Financial Markets, Institutions, and Money, Journal of Asset Management, and Research in International Business and Finance, and serves as a reviewer for Finance Research Letters and Research in International Business and Finance. His research interest covers various topics in the discipline, including international investment, financial risk management, market efficiency and cryptocurrency. He has done consulting works for a number of business firms and government organizations, including Select Sector SPDRs, Rakuten, Inc., Citrix Systems, Inc., and Middlebury College. 